\title{
UMA TECNOLOGIA DE PROCESSO APLICADA AO ACOMPANHANTE DO IDOSO HOSPITALIZADO PARA SUA INCLUSÃO PARTICIPATIVA NOS CUIDADOS DIÁRIOS ${ }^{1}$
}

\author{
Maria Luiza de Oliveira Teixeira², Márcia de Assunção Ferreira ${ }^{3}$
}

\begin{abstract}
${ }^{1}$ Recorte da tese "Uma tecnologia de processo aplicada junto ao acompanhante no cuidado ao idoso: contribuições à clínica do cuidado de enfermagem". Escola de Enfermagem Anna Nery (EEAN) da Universidade Federal do Rio de Janeiro (UFRJ), 2008.

${ }^{2}$ Doutora em Enfermagem. Professor Adjunto do Departamento de Enfermagem Fundamental da EEAN/UFRJ. Rio de Janeiro, Brasil. E-mail: mlot@uol.com.br

${ }^{3}$ Doutora em Enfermagem. Professor Titular do Departamento de Enfermagem Fundamental da EEAN/UFRJ. Rio de Janeiro, Brasil. E-mail: marciadeaf@ibest.com.br
\end{abstract}

RESUMO: A participação passiva do acompanhante do idoso hospitalizado no seu cuidado diário originou esta pesquisa, cujos objetivos foram: descrever uma tecnologia de processo aplicada junto ao acompanhante que permita sua inclusão no cuidado ao idoso hospitalizado; discutir limites e possibilidades de sua implementação no cuidado a este. Trata-se de uma pesquisa convergenteassistencial com apoio teórico em Freire e Leininger. Os sujeitos foram 19 acompanhantes de idosos hospitalizados. Os dados foram coletados por meio de entrevistas e observação participante com posterior análise temática de conteúdo. A inclusão do acompanhante foi desenvolvida por meio de ações operacionalizadas de forma sistemática, articulando conhecimentos científicos e do senso comum, fundamentada em conceitos teóricos. Implica em uso de técnicas procedimentais, interativas e clínicas. Configurou-se em uma tecnologia de processo bem avaliada pelos acompanhantes, levando-os ao protagonismo e a um fazer mais autônomo no compartilhamento do cuidado ao idoso hospitalizado, consoante à Política Nacional de Humanização.

DESCRITORES: Tecnologia em saúde. Educação em saúde. Acompanhantes de pacientes. Idoso. Enfermagem.

\section{PROCESS TECHNOLOGY APPLIED TO HOSPITALIZED ELDERLY COMPANIONS FOR THEIR PARTICIPATIVE INCLUSION IN DAILY CARE}

\begin{abstract}
The passive participation of the hospitalized elderly companion in daily care gave rise to this study, which aimed to: describe a process technology which allows the companion's inclusion in hospitalized elderly care; and discuss limits and possibilities of its implementation in hospitalized elderly care. This is a convergent-supportive study with theoretical support from Freire and Leininger. The subjects were 19 companions of hospitalized elderly. Data was collected through interviews and participant observation with subsequent thematic content analysis. The inclusion of the companion was developed through systematic actions, linking scientific knowledge and common sense, founded on theoretical concepts. It implies the use of procedural, interactive, and clinical techniques. It was configured in a process technology which was well-evaluated by companions, leading them to be more protagonistic and to more autonomous action in sharing care of the hospitalized elderly, according to National Politics of Humanization.
\end{abstract}

DESCRIPTORS: Biomedical technology. Health education. Patient escort service. Aged. Nursing.

\section{UNA TECNOLOGÍA DE PROCESO APLICADA AL ACOMPAÑANTE DEL ANCIANO HOSPITALIZADO PARA SU INCLUSIÓN PARTICIPATIVA EN LOS CUIDADOS DIARIOS}

\begin{abstract}
RESUMEN: La participación pasiva del acompañante del anciano hospitalizado en su cuidado diario originó esta investigación, cuyos objetivos fueron: describir una tecnología de proceso aplicada al acompañante que permita su inclusión en el cuidado al anciano hospitalizado; discutir los límites y posibilidades de su implementación en el cuidado al anciano. Se trata de una investigación convergente asistencial basada en las teorías de Freire y Leininger. Los sujetos fueron 19 acompañantes de ancianos hospitalizados. Los datos fueron recolectados por medio de entrevistas y observación participativa, con posterior análisis temático de contenido. La inclusión de los acompañantes fue desarrollada por medio de acciones sistemáticas que vinculan el conocimiento científico y el sentido común, basada en conceptos teóricos, lo cual implica en el uso de técnicas de procedimiento, interactivas y clínicas. Se caracteriza por ser una tecnología de proceso que fue bien evaluada por los acompañantes, lo que los llevó a la autonomía compartida en el cuidado de los ancianos hospitalizados, según la Política Nacional de Humanización.
\end{abstract}

DESCRIPTORES: Tecnología biomédica. Educación en salud. Acompañantes de pacientes. Anciano. Enfermería. 


\section{CONSIDERAÇÕES INICIAIS}

A inserção no hospital do acompanhante ao idoso hospitalizado se dá de acordo com a lógica que sustenta a organização da assistência hospitalar, qual seja, a do modelo biomédico que preconiza a atenção voltada para a patologia e sua cura, na qual o cliente assume um papel passivo e pouco (ou nada) participativo.

Nesta lógica, ainda que se tenham iniciativas voltadas a situar o cliente no seu tratamento, estimulando-o à participação, esta se dá em um modelo verticalizado, que é o da transmissão de informações sustentada em ordens prescritivas que muitas vezes não alcançam o objetivo de inserção do cliente no processo e no desenvolvimento de sua autonomia no cuidado, já que esta condição exige uma tomada de consciência da situação que permita sua participação consciente. E para que haja a tomada de consciência é preciso que ele se veja no processo do cuidado, como ativo participante. No entanto, a participação ativa em qualquer processo só se faz possível quando todos os envolvidos nas ações se sentem com igual direito de expressão. Contudo, no campo do cuidado em saúde, pouco se sabe (ou se procura saber) sobre as vivências e experiências acumuladas pelos clientes e suas famílias sobre o cuidado. Não se abre a possibilidade de diálogo com esses clientes, que permita acessar seus saberes e práticas advindas de sua herança cultural, bem como aqueles incorporados do universo científico.

Os discursos atualmente veiculados na área da saúde privilegiem a abordagem holística, centrada no ser humano, e o reconhecimento da cidadania do cliente, o que significa atentar para os direitos e deveres dos sujeitos, na prática assistencial hospitalar. No entanto, o atendimento, via de regra, se dá de forma diretiva que pouco privilegia ou estimula a participação do cliente e do acompanhante no todo da assistência e do cuidado de enfermagem, fato este contrário a um dos princípios do Sistema Único de Saúde (SUS), o princípio da integralidade. O referido princípio preconiza que as ações de saúde devam ser combinadas e voltadas ao mesmo tempo para a prevenção e a cura. Estas ações de promoção, proteção e de recuperação formam um todo indivisível que não podem ser compartimentalizadas.

Ao considerar o cliente idoso hospitalizado que traz a presença do acompanhante por força da Lei $N^{\circ} 8842$ de 4 de janeiro de $1994,{ }^{1}$ a enfermagem tem, na verdade, dois clientes: o próprio idoso e o acompanhante. A garantia deste direito foi viabi- lizada pela Portaria $\mathrm{N}^{\mathrm{o}} 280$, de 7 de abril de 2006, do Ministério da Saúde. ${ }^{2}$ A oportunidade que a lei oferece ao prever a permanência do acompanhante ao idoso hospitalizado merece ser aproveitada no sentido de favorecer sua participação ativa no cuidado ao cliente. No entanto, ainda que através de uma observação assistemática, é possível identificar que, no dia-a-dia dos serviços de saúde, ditos de caráter curativo, tal participação, quando ocorre, na maioria das vezes, é passiva, pois tanto os clientes como seus acompanhantes obedecem às prescrições dos profissionais de forma mecânica, sem propriamente, serem preparados para entender os porquês dos cuidados.

No entanto, para que esta participação se torne efetiva, há que se lançar mão de um recurso por meio do qual se viabilize o intercâmbio entre o saber técnico-científico (profissional) e o popular (senso comum). Tal recurso estaria situado no campo da educação em saúde, como estratégia de cuidado, a qual "constitui um conjunto de saberes e práticas orientado para a prevenção de doenças e promoção de saúde" 3:43 De acordo com esta definição, podese entender que a educação em saúde proporciona "construção compartilhada de conhecimento". 4:101

As ações de educação em saúde podem ter os mais variados enfoques. Nesta pesquisa, o enfoque dado é o da prevenção e tratamento das úlceras por pressão, já que esta se configura como uma situação-problema emergente do cenário hospitalar no atendimento de idosos acamados. A preocupação central com os idosos dependentes coloca os seus acompanhantes no centro da problemática, pois os idosos constituem uma população de risco para o desenvolvimento da úlcera por pressão e, na maioria das vezes, não têm condições para se cuidar, gerando a dependência para realizar o cuidado de si, o que demanda alguém com o mínimo de preparo para atuar provendolhe o autocuidado. Além disso, as úlceras por pressão configuram-se em problema de grande magnitude, pois afetam clientes hospitalizados como também aqueles sob tratamento no domicílio. Na dependência da localização e do estágio de desenvolvimento, as lesões podem ser difíceis de serem tratadas e frequentemente resultam em dor, distúrbio da auto-imagem e prolongam a hospitalização, o que aumenta sensivelmente a demanda de gastos financeiros. ${ }^{5}$ Os gastos com o setor saúde, bem como os muitos problemas que vivenciamos no campo da saúde pública vêm requerendo soluções criativas para as questões que se colocam no cotidiano assistencial. 
Desta forma, parte-se do pressuposto que o cenário hospitalar possa ser considerado como um ambiente de cuidado e seja configurado não somente para a realização de ações de natureza assistencial verticalizada, mas para possibilitar o desenvolvimento de estratégias includentes que conduzam o acompanhante a participar ativamente do cuidado junto ao idoso hospitalizado, uma vez que este possui saberes e práticas de cuidado que não devem ser negligenciados e precisam ser valorizadas pelo universo profissional.

Assim, os objetivos desta pesquisa são: descrever uma tecnologia de processo aplicada junto ao acompanhante que permita sua inclusão no cuidado ao idoso hospitalizado; discutir limites e possibilidades da implementação desta tecnologia no cuidado ao idoso hospitalizado.

O referencial teórico que sustenta o desenvolvimento da tecnologia de processo em tela e a discussão dos resultados advindos da aplicação é o da Pedagogia Freiriana, em articulação com conceitos presentes na Teoria de Leininger, no que couber ao campo do cuidado à saúde e da enfermagem, cultura, cuidado de enfermagem culturalmente diverso e enfermagem transcultural.

Os resultados obtidos, através do acesso à Biblioteca Virtual da Saúde - BIREME, ao Catálogo de Pesquisas do Centro de Estudos e Pesquisas em Enfermagem da Associação Brasileira de Enfermagem (no período de 1979 a 2004) e ao Banco de Teses da Coordenação de Aperfeiçoamento de Pessoal de Nível Superior, no levantamento do estado da arte no que pese ao interesse específicos desta pesquisa, nos levam a considerar que muitas enfermeiras têm utilizado as idéias freirianas como condutoras de sua prática educativa aliada a sua prática assistencial, voltada tanto para o cliente como para a família. Além disso, o enfoque centrase na avaliação da aplicação imediata das propostas desenvolvidas no final do processo e não a longo prazo, o que demonstra a necessidade de uma avaliação mais criteriosa do processo educativo. Frente a esta consideração, considera-se que os resultados apresentados nos estudos captados nas bases de dados não são parâmetros objetivos com os quais se pode afirmar que as propostas desenvolvidas na prática educativa tiveram sucesso.

\section{ABORDAGEM METODOLÓGICA}

Pesquisa qualitativa com aplicação do método convergente-assistencial. Este tipo de pesquisa está comprometido com a melhoria direta do contexto social pesquisado e inclui uma variedade de métodos e técnicas pelo fato de que, além de obter informações, o pesquisador envolve os sujeitos pesquisados ativamente no processo do cuidado. ${ }^{6}$

Para a condução da proposta de pesquisa em tela foi preciso eleger um tema que pudesse servir de fio condutor à elaboração da estratégia de inclusão do acompanhante, no sentido de se evidenciar seus saberes e práticas de cuidado. Considerou-se, então, a situação do idoso hospitalizado e os cuidados com a pele, especificamente no que tange a prevenção e tratamento de úlceras por pressão, uma vez que esta clientela é bastante vulnerável a este problema. Aliado a isso, se considerou que, quando no domicilio, a vulnerabilidade permanece e os saberes e práticas sócio-familiares são aplicados no seu cuidado.

Foram sujeitos do estudo 19 acompanhantes de idosos internados na clínica médica de um Hospital Universitário público federal do município do Rio de Janeiro. Realizaram-se entrevistas em grupo e individualmente.

Em atendimento à proposta metodológica da Pesquisa Convergente-Assistencial, a pesquisa se desenvolveu em quatro etapas. 1) Inicialmente, foi preenchido um instrumento de identificação com a finalidade de caracterizar o idoso e o acompanhante. Neste instrumento foram levantados aspectos implicados na construção dos discursos dos sujeitos sobre o objeto de estudo. Tanto para Leininger, ${ }^{7}$ quanto para Freire, ${ }^{8}$ é necessário um conhecimento prévio da realidade do sujeito para entender melhor seu universo. Os sujeitos eram familiares dos idosos, com exceção de duas pessoas que eram pagas pelas famílias. Formaram um grupo com pouca diversidade em termos sócio-econômicos, pois a tendência majoritária foi de pessoas da classe trabalhadora, com baixo poder econômico e segundo grau completo como escolaridade predominante. 2) Foi estabelecido o diálogo com os sujeitos sobre o tema prevenção e tratamento de úlceras por pressão com vistas a fazer fluir dos sujeitos os seus saberes e práticas e também os da pesquisadora sobre o tema. A partir do relato do sujeito acerca das suas construções, desencadeou-se a discussão visando compartilhar os saberes e práticas, bem como o processo de problematização. Simultaneamente a esta fase se deu a execução de estratégia em que o sujeito elaborou, à luz do que foi discutido, uma proposta de cuidados a ser implementada por ele na prevenção e tratamento de úlceras por pressão. 3) Esta fase ocorreu a partir da aplicação da técnica de obser- 
vação participante que consistiu na observação, na enfermaria, do acompanhante no contato com o idoso com vistas a captar o desenvolvimento dos cuidados implementados por ele. Como parte desta técnica, foram estabelecidos diálogos com os sujeitos com o intuito de buscar a interpretação deles para o que foi observado, evitando-se trabalhar, somente, com a perspectiva interpretativa da pesquisadora. 4) $\mathrm{O}$ acompanhante foi novamente reunido para discutir individualmente com a pesquisadora o observado, e permitir aos sujeitos fazer considerações sobre todo o processo. Ao corpus de dados aplicou-se a análise temática de conteúdo, com vistas a buscar as unidades de registro e de contexto que conformassem as categorias empíricas para análise e posterior discussão. ${ }^{9}$ Os conteúdos mais significativos se aglutinaram em torno de dois grandes temas: sobre as estratégias de cuidado e ação dos acompanhantes junto ao idoso; e sobre as relações estabelecidas com a equipe e as possibilidades de mudança de status do acompanhante.

A pesquisa atendeu a Resolução No 196/96 do Conselho Nacional de Saúde que trata de pesquisas com seres humanos, sendo aprovada pelo Comitê de Ética em Pesquisa do Hospital, que serviu de lócus para a pesquisa, sob o protocolo $\mathrm{N}^{\mathrm{o}}$ 002/07. O Termo de Consentimento Livre e Esclarecido foi assinado por todos os sujeitos. A identificação dos depoimentos foi feita por códigos alfanuméricos. Os acompanhantes foram identificados pela letra $\mathrm{A}$, seguida números arábicos sequenciais. Um idoso estava sendo acompanhado por três acompanhantes, neste caso, estes foram identificados acrescentando as letras b e c à sequência da letra A e ao número arábico.

\section{APRESENTAÇÃO E DISCUSSÃO DOS RESULTADOS}

As características do modelo biomédico, principalmente o fato de o foco da atenção ser dada à doença, não permitem, na maioria das vezes, a inclusão do acompanhante do idoso hospitalizado no processo de cuidado.

Esta dificuldade de inclusão dos acompanhantes no cuidado ao idoso pode estar relacionada ao fato dos acompanhantes integrarem redes sociais de apoio. Estas redes podem ser formais ou informais. ${ }^{10}$ Em aproximação com a Teoria de Leininger, as redes de apoio se assemelham aos sistemas populares (informal) e aos sistemas profissionais de cuidado (formal).
Na maioria, os acompanhantes enquadramse nas redes de apoio informal, e quando se encontram no hospital, rede-formal, se deparam com uma organização que aplica conhecimentos científicos e tecnológicos, com normas e rotinas a serem seguidas, diferentes das do seu cotidiano.

As concepções reducionistas de saúde e doença do modelo biomédico vêm sofrendo críticas com a emergência de um novo paradigma. Está sendo enfatizado o deslocamento da concepção de neutralidade e objetividade presentes no modelo biomédico, para a subjetividade e o resgate de valores como democracia, ética e respeito aos sentimentos e valores dos pacientes, de seus familiares e dos profissionais de saúde.

É preciso superar a dimensão prescritiva do cuidado e caminhar no sentido de reconhecer que na relação entre a enfermeira e o acompanhante, ambos os sujeitos devem ter espaço e voz no processo, com respeito às diferenças de valores e de expectativas.

Desse modo, no desenvolvimento da tecnologia de processo de inclusão do acompanhante no cuidado ao idoso, proposta nesta pesquisa, o diálogo permitiu que este, junto com a pesquisadora, elaborasse um plano de cuidados voltado para a prevenção e tratamento de úlceras por pressão no ambiente hospitalar, considerando especialmente seus saberes e práticas oriundos de vivências prévias, como também aqueles que foram frutos da reflexão realizada no diálogo com a pesquisadora, durante o desenvolvimento da referida tecnologia. Este diálogo "pretende, em qualquer hipótese, [...] a problematização do próprio conhecimento em sua indiscutível reação com a realidade concreta na qual se gera e sobre a qual incide, para melhor compreendê-la, explicá-la, transformá-la" ${ }^{11: 52} \mathrm{O}$ plano de cuidados elaborado constou de ações gerais a serem seguidas pelos acompanhantes.

A enfermaria foi o espaço em que se deu a participação no cuidado ao idoso hospitalizado pelo acompanhante através da execução do plano de cuidados. Ele saiu da condição de apenas acompanhar, para ser partícipe do cuidado, saiu dos bastidores para ocupar um espaço no cenário principal.

O espaço físico da enfermaria, do setor de clínica médica, foi entendido como espaço social, profissional e de relações interpessoais onde aconteceu o encontro do sistema popular com o sistema profissional de cuidado.

Com a aplicação da técnica de observação participante, que consistiu na observação, na enfermaria, do acompanhante no contato com o 
idoso, foi possível captar o desenvolvimento dos cuidados implementados por ele. Como parte desta técnica, foram estabelecidos diálogos com os sujeitos sobre todo o processo, no qual tiveram a oportunidade de emitir suas opiniões e avaliações sobre as suas participações no cuidado ao idoso, evitando-se, assim, que os dados gerados na pesquisa viessem, apenas, das observações e avaliações da própria pesquisadora.

\section{Estratégias de cuidado e de ação dos acom- panhantes}

Alguns acompanhantes estabeleceram como ação para prevenir o aparecimento das úlceras por pressão a utilização de travesseiros e almofadas para o reposicionamento corporal e elevação do calcâneo. Com isso, se depararam com uma situação-problema: tais recursos são necessários em quantidade maior do que a oferta pela instituição, pois havia, apenas, um travesseiro por paciente.

Duas acompanhantes abandonaram a acomodação, que é o procedimento passivo e não refletido de alguém que perdeu a capacidade de escolha e, por isso, ajusta-se ao que lhe é imposto, não cria, não recria, nem decide, pois, em resposta à situação-problema referida, lançando mão da ação-reflexão-ação transformadora, se mobilizaram e decidiram contribuir da seguinte forma: uma trouxe de sua casa quatro travesseiros (A6) e outra (A5) confeccionou, ela própria, 10 travesseiros pequenos, que, segundo ela, foram feitos menores e mais macios para melhor se adaptarem ao corpo de seu pai, que estava muito magro, proporcionandolhe mais conforto.

Estas acompanhantes conseguiram identificar o que precisava ser mudado na realidade do cenário, e intervir nesta realidade em prol da qualidade do cuidado ao idoso que acompanhavam, caracterizando bem o que o método freiriano preconiza com a problematização.

Outros acompanhantes também tiveram esta postura quando trouxeram de casa o hidratante para ser aplicado na pele dos idosos (A1, A2, A3, A3b, A3c, A4, A7, A16).

Esse quadro relatado demonstra que a pesquisa proporcionou um movimento de responsabilização. Quando as pessoas vão para o centro da ação, tomam consciência da necessidade de comprometimento com a situação. No momento em que o sistema profissional não ofereceu os recursos materiais e profissionais necessários para a realização do cuidado ao cliente, houve uma mobilização por parte das acompanhantes, que estavam sensibilizadas, no sentido de suprirem esta falta.

O diálogo levou os acompanhantes a identificarem a observação da pele e do estado geral do idoso como um cuidado preventivo, pois através da observação é possível detectar situações que mereçam a implementação de ações que evitam o aparecimento das úlceras por pressão. Destacase que tanto na prevenção quanto no tratamento da úlcera por pressão, a observação se torna importante.

A acompanhante A3b durante o banho da idosa, realizado no leito, observou e inspecionou as áreas de proeminências ósseas: tem que olhar, para fazer alguma coisa antes da ferida, da úlcera aparecer....

Quando indagada sobre o que estaria observando, a acompanhante respondeu que observava se estava vermelho, pois já é sinal que pode aparecer a úlcera... (A3b).

Ter que fazer alguma coisa antes da ferida aparecer (A3b) caracteriza a observação dirigida ao cuidado preventivo.

O comportamento destes acompanhantes nos leva a crer que se trata de uma participação mais ativa e consciente no cuidado ao idoso.

\section{As relações entre equipe e acompanhante: possibilidades de mudança de status}

Nesta pesquisa, ao propor ao acompanhante o cuidado compartilhado, foi introduzida uma estratégia que poderia estimular as potencialidades deste acompanhante no que diz respeito ao cuidado ao idoso. Neste contexto, se fez presente a participação da equipe de saúde, em especial, a da equipe de enfermagem.

No entanto, houve relatos de acompanhantes que se ressentiram por não terem recebido uma resposta mais efetiva de alguns elementos da equipe de enfermagem no reconhecimento de seu cuidado junto ao idoso.

Não, nem elogiaram e nem recriminaram (A5).

É interessante notar que as acompanhantes, ao tecerem estes comentários, ressaltaram que a equipe de enfermagem não interferiu e nem repreendeu as suas atuações no cuidado ao idoso.

Não, ninguém atrapalhou, nem falou nada. Elas são tranqüilas, não incomodam (A6).

Não, não teve nenhum comentário. Se tivessem repreendido na hora eu ia falar que tava fazendo o que ensinaram (A5). 
Elas não foram ásperas comigo não, elas deixaram, não interferiram em nada não (A3b).

Não interferem, eu acho que só vão falar se tiver alguma coisa fora do que tiver que ser feito, aí eles devem falar (A16).

Na análise temática de conteúdo, identificase nestas duas unidades de registro (A3b e A16), que há por parte das acompanhantes uma tentativa, um ensaio de mudança da relação estabelecida entre acompanhante e equipe de enfermagem. O acompanhante é visto, na maioria das vezes, como submisso, que segue as normas e rotinas estabelecidas pelo sistema profissional. Neste sentido, vemos que os resultados em tela vêm na contramão do que, habitualmente, identifica-se nas pesquisas que tratam sobre a relação de poder entre os agentes/sujeitos que convivem no espaço hospitalar. O hospital, como espaço legítimo de aplicação do saber profissional, organiza-se assentado em uma rígida disciplina dos corpos de todos que lá convivem. Há mecanismos aplicados na disciplinarização dos comportamentos dos agentes/sujeitos na dependência da sua categoria: paciente, profissional e acompanhante. ${ }^{13}$

Muitas estratégias são adotadas no cotidiano com vistas a diminuir a força reivindicatória dos pacientes/acompanhantes, através de atos que vão, gradativamente, despersonalizando os sujeitos. ${ }^{14}$ Como exemplo podemos citar a nominação dos pacientes pelo número da enfermaria/ leito e/ou pela patologia e, no caso do idoso, por um "parentesco imaginário" atribuído a ele pela idade: vovô/vovó.

Quando este mesmo acompanhante começa a ver a equipe como alguém que pode atrapalhá-lo ou demonstra possibilidades de reagir a uma repressão (A5), mostra a tentativa/investimento que eles estão fazendo para mudar sua posição hierárquica em relação à equipe. Talvez seja uma tentativa de tornar a relação horizontal, onde o respeito deva acontecer, cada qual representante de um sistema, o profissional e o popular, compartilhando o mesmo espaço com o mesmo objetivo: o cuidado ao idoso.

Há de se fazer reflexões sobre a questão levantada pelos acompanhantes de que a equipe de enfermagem possa atrapalhar a atuação deles com o idoso. Para se ter um acompanhante que compartilha o cuidado com a equipe de enfermagem, esta necessita de preparo para saber lidar com ele. Logo, quando o acompanhante diz que a equipe pode atrapalhar ou repreender, percebemos uma nova atitude que pode ter sido despertada pelo diálogo e reflexão estabelecidos durante a pes- quisa, pois sua autonomia foi estimulada, porém a equipe não participou diretamente deste diálogo e reflexão. A atuação da equipe ainda é baseada no modelo tradicional, biomédico, com medidas prescritivas, por vezes autoritárias, o que para este novo acompanhante não é mais admissível.

Esta situação é ilustrada na fala de uma das acompanhantes, que durante a reflexão sobre a atuação da equipe de enfermagem, chamou a atenção quanto a um aspecto negativo da conduta da equipe que não permite a utilização dos cremes preparados por ela mesma.

Se a gente pudesse usar o creme que a gente usa em casa, aquele que a gente coloca uma erva, a pele dele estaria melhor, mas como não estamos usando... você tem que se limitar a usar aquilo que o hospital permite (A16).

Assim sendo, o processo de instauração de uma tecnologia de processo de inserção do acompanhante no cuidado, proposta desta pesquisa, não deve ingenuamente ser confundido com a constituição de um ambiente sem limites para a atuação, no qual a participação do acompanhante seja um mero instrumento de legitimação de interesses próprios. Cabe ao sistema profissional respeitar a liberdade de escolha e fornecer as informações necessárias, contemplando o intercâmbio de saberes, tendo em mente que na medida em que o acompanhante exerça sua autonomia, estará também exercendo sua cidadania.

Há fatores e valores de diversas ordens que influenciam e são influenciados no/pelo cuidado. ${ }^{5}$ Tais fatores/valores integram tanto o sistema profissional quanto o popular. Neste ínterim, a enfermagem como ciência e arte do cuidado às pessoas exerce o papel de possibilitar o diálogo entre estes dois sistemas sem, no entanto, ter a pretensão de unificá-los ou hierarquizá-los, mas investir em estratégias que possam integrá-los.

A participação do acompanhante e esse diálogo aconteceram na pesquisa porque fazia parte do processo inerente à investigação, ou seja, emergiu como uma obrigatoriedade por conta das etapas metodológicas do projeto. Para que seja aplicado na assistência, há também a necessidade de que faça parte do planejamento assistencial, ou seja, que conste das suas etapas, pois para a ação pedagógica libertadora é imprescindível a compreensão da totalidade e da dialética do processo, em que o sujeito que sofre as determinações do planejado é também aquele que planeja. ${ }^{15}$

Na avaliação da acompanhante A12, a equipe de enfermagem aprovou sua participação, e até 
mesmo gostou, pois segundo ela, o trabalho da equipe foi facilitado.

Olha só, é no caso assim, não reclama porque eles não têm trabalho, o único trabalho que eles têm é de ir lá dar medicação, e trocar os pacientes. Algumas olham, observam, fazem perguntas, algumas ficam quietas, assim, mas em momento algum ninguém nunca gostou, assim todas gostaram, porque facilita também o trabalho delas (A12).

A reflexão realizada por A12 mostra ainda a idéia errônea de que o acompanhante é um complemento de recursos humanos para a assistência de enfermagem.

$\mathrm{Na}$ análise dos dados identifica-se que a equipe de enfermagem não percebeu a diferença de atuação destes acompanhantes. $\mathrm{O}$ fato de ficar indiferente e até mesmo considerar a atuação como facilitador do trabalho demonstra que o processo de compartilhar o cuidado deve ser desenvolvido em mão-dupla com os sujeitos que estão inseridos no mesmo contexto. É preciso dialogar para que ambos possam realizar uma leitura crítica sobre sua inserção no cuidado ao idoso. "Devemos estar atentos para o fato de que, quando se inicia um processo de transformação, a primeira resposta pode não ser a melhor, pois é fruto do autoritarismo assimilado, lembrando a questão do opressor e do oprimido, levantada por Paulo Freire" . 15:27

A leitura que os acompanhantes fizeram sobre a equipe de enfermagem é resultado da influência do modelo biomédico nas relações entre profissionais e clientes e/ou acompanhantes.

Diante do cumprimento de todas as fases propostas por esta pesquisa, da mesma forma que foi dado ao acompanhante a oportunidade de avaliar o processo do cuidado compartilhado, do qual foi o protagonista, a pesquisadora também fez a avaliação.

A última fase da pesquisa convergenteassistencial, a interpretação, compreende três processos fundamentais correspondentes à lógica da análise de seus achados, discriminados como: síntese, teorização e transferência. ${ }^{5}$

Neste momento, destaca-se o processo de transferência de resultados. Este processo na pesquisa convergente-assistencial " consiste na possibilidade de dar significado a determinados achados ou descobertas e procurar contextualizá-los em situações similares, sem que esse processo venha a ser entendido como poder de generalizações" .5:96

O desenvolvimento da pesquisa mostrou que é possível ter um outro olhar na abordagem do acompanhante. Esta abordagem utilizou a educação em saúde como estratégia de cuidado e se deu através do intercâmbio de saberes cultural-socialfamiliar e científico no espaço do hospital.

Percebe-se que a articulação do referencial teórico utilizado com a metodologia da pesquisa convergente-assistencial se configurou como uma tecnologia utilizada no processo dialógico construído com o acompanhante. Processo este que considera o sujeito na ação com a utilização de estratégias de inclusão, como o diálogo/reflexão. Neste sentido, a pesquisa atendeu a uma das classes de resultados esperados, qual seja: "ampliação desses resultados em processo, na ótica da cobertura do cenário assistencial como um todo, de modo a explicitar seus reflexos na qualidade da assistência desenvolvida no âmbito de atuação da pesquisa" . 5:97

Estas considerações também permitem associar o processo dialógico construído com o acompanhante a uma tecnologia. Isto deveu-se ao fato de se considerar a tecnologia como "Um conjunto de conhecimentos (científicos e empíricos) sistematizados, em constante processo de inovação, os quais são aplicados pelo profissional de enfermagem em seu processo de trabalho, para o alcance de um objetivo específico. Permeada pela reflexão, interpretação e análise, essa é subsidiada pela experiência profissional e humana. A característica da tecnologia em enfermagem é peculiar, pois ao se cuidar do ser humano, não é possível generalizar condutas, mas sim adaptá-las às mais diversas situações, a fim de oferecer um cuidado individual e adequado ao indivíduo" ${ }^{16: 120-1}$

O processo dialógico construído com o acompanhante desenvolvido na pesquisa apresentou uma organização e uma possível sistematização das atividades, podendo contribuir para a clínica do cuidado de enfermagem, por isso pode ser considerado como uma tecnologia, considerando que "a tecnologia moderna não só produz máquinas e ferramentas físicas, mas também organiza e sistematiza as atividades" ${ }^{17: 180} \mathrm{O}$ que nos leva a compreender que a tecnologia abarca um conjunto de ferramentas que dá dinamicidade às ações. Para tanto, há que se considerar "os recursos materiais e imateriais dos atos técnicos e dos processos de trabalho". ${ }^{18: 248}$

Este processo constitui uma tecnologia porque comporta um conjunto de ações que são operacionalizadas de forma sistemática, articulando conhecimentos de dois universos: científico e senso comum, fundamentada em conceitos teóricos. Implica em uso de técnicas procedimentais, interativas e clínicas. 


\section{CONCLUSÕES}

A tecnologia de processo que se apresentou ao final do desenvolvimento da pesquisa, se sustentou no debate teórico da valorização da cultura de saberes dos sujeitos envolvidos no cuidado. Tanto na prática educativa de Freire, quanto nas práticas de cuidado de Leininger, o reconhecimento e o respeito da identidade cultural são importantes, como também o é no método da pesquisa convergente-assistencial para que se atinja, de fato, a convergência de forma participativa com os sujeitos e não impositiva a eles.

É oportuno destacar que, ao propor uma tecnologia de processo de inclusão do acompanhante que o torne co-partícipe do cuidado ao idoso hospitalizado, há de considerá-lo como sujeito representante do sistema popular inserido no sistema profissional. Esta proposta é um desafio, pois estabelece novas relações dentro de antigas estruturas. Tais relações influenciadas pela cultura própria de cada sistema e da estrutura maior que é o modelo biomédico.

Nessa linha de raciocínio, outras questões podem também ser destacadas como limites para a implementação da proposta que considera a integração dos saberes popular e profissional na elaboração de um plano de cuidados. Para haver esta integração de saberes, a pesquisa utilizou do diálogo/reflexão como condutor do processo, e para tanto é necessário que se estabeleça uma relação de empatia entre profissional e acompanhante. Se não ocorrer a empatia, o processo pode não atingir os objetivos. Características pessoais como a timidez e cultura pessoal dos envolvidos no processo podem se configurar como um obstáculo a ser superado.

É necessário que os profissionais se qualifiquem no sentido de obter conhecimentos sobre os princípios teóricos que regem a proposta para permitir sua atuação. Para dar conta desta proposta, cabe ao sistema profissional, além de qualificar, disponibilizar um número maior de profissionais, pois este tipo de proposta demanda um tempo maior de dedicação por parte da enfermeira. Esta questão se torna um grande desafio, haja vista as dificuldades que as instituições de saúde atravessam com relação ao número de recursos humanos. Para obter êxito é necessário que a equipe de saúde esteja engajada, disposta e coesa para aplicar a proposta.

O que se vê atualmente, entretanto, é que existe um movimento desencadeado pela transição paradigmática vigente, de valorização de ações que utilizam elementos do paradigma emergente, ações estas que deixam de lado a dimensão estritamente biológica do processo saúde-doença. Então, a proposta de tecnologia de processo aqui discutida encontra uma possibilidade de implementação.

Um exemplo desta transição paradigmática é a construção da Política Nacional de Humanização no Sistema Único de Saúde. Esta política valoriza os diferentes sujeitos implicados no processo de produção de saúde: usuários, trabalhadores e gestores. Os valores que norteiam esta política são a autonomia e o protagonismo dos sujeitos, a co-responsabilidade entre eles.

O conhecimento compartilhado entre enfermeira e acompanhante através do diálogo/reflexão deu condições ao acompanhante de desenvolver certa autonomia e responsabilidade no cuidado ao idoso, despertando o pensamento crítico no que diz respeito à prevenção e tratamento das úlceras por pressão.

É fato que a falta de recursos para os cuidados fundamentais de enfermagem retrata a realidade de sucateamento dos serviços de saúde. Não obstante a isto, o que esta pesquisa evidenciou é que, uma vez os acompanhantes tomando ciência da necessidade de determinados cuidados, identificam as carências e, para proporcionar um melhor cuidado ao idoso, lançam mão do conhecimento compartilhado para reivindicar melhores condições para a prática do cuidado. Além do que, no momento em que se torna co-responsável pelo cuidado, o acompanhante passa a se ver como parte da engrenagem da dinâmica hospitalar e começa a participar inclusive dos problemas que a equipe enfrenta, podendo se tornar um aliado da equipe de enfermagem no processo de reivindicação por melhores condições de oferta do cuidado de enfermagem.

Deste modo, a tecnologia de processo proposta nesta pesquisa é um caminho interessante de reivindicação que tem no acompanhante um sujeito responsável e autônomo. A referida proposta apresenta implicações que vão além do cuidado direto ao idoso. Passa por implicações administrativas, já que uma reivindicação merece uma avaliação e uma solução, e para tal, os vários níveis da hierarquia administrativa precisam ser mobilizados. Podem-se destacar também implicações sociais, pois o idoso é uma categoria vulnerável, objeto de políticas públicas sociais e de saúde. Nestas políticas, o acompanhante é destacado. Ao integrar o acompanhante no cuidado ao idoso, a proposta que se apresenta pode proporcionar 
qualidade de vida, conforto e bem-estar ao idoso, diminuindo a possibilidade de agravamento do quadro e o período de internação.

Outra possibilidade de sua implementação é a adaptação da organização do trabalho de enfermagem, de modo a favorecer o desenvolvimento da proposta. Como por exemplo, desenvolvê-la no período da tarde, quando ocorre uma redução da circulação de profissionais que atuam no cenário hospitalar, diminuindo as demandas de solicitações para a equipe de enfermagem.

Amparado nos resultados, confirmou-se o pressuposto de que o cenário hospitalar pode ser considerado como um ambiente de cuidado passível de ser reconfigurado para realização de ações compartilhadas, através do desenvolvimento de estratégias includentes que conduzam o acompanhante a participar ativamente do cuidado junto ao idoso hospitalizado, não como mão-de-obra utilitária para suprir as carências de pessoal, mas para melhor prepará-lo para o cuidado do idoso no domicílio, evitando-se assim, reincidência dos problemas com consequente reinternação.

Isto porque, os resultados desta pesquisa mostraram que o cuidado básico/fundamental para a manutenção da integridade da pele do idoso foi passível de ser construído a partir do intercâmbio de saberes sócio-familiar e científico, efetivamente realizado, contribuindo para a clínica do cuidado de enfermagem.

\section{REFERÊNCIAS}

1. Brasil. Ministério da Previdência e Assistência social. Política Nacional do Idoso: Lei No 8842 de 4 de janeiro de 1994. Brasília (DF): MPAS, SAS; 1997.

2. Ministério da Saúde (BR). Portaria No 2528 de 19 de outubro de 2006. Aprova a Política Nacional de Saúde da Pessoa Idosa. Brasília (DF): MS; 2006.

3. Alves VS. Um modelo de educação em saúde para o Programa Saúde da Família: pela integralidade da atenção e reorientação do modelo assistencial. Interface - Comunic Saúde Educ. 2005; 9(16):39-52.

4. Carvalho MAP, Acioli S, Stotz EN. O processo de construção compartilhada do conhecimento: uma experiência de investigação do ponto de vista popular. In: Vasconcelos EM, organizador. A saúde nas pala- vras e nos gestos: reflexões da rede popular e saúde. São Paulo (SP): Editora Hucitec; 2001. p.101-44.

5. Trentini M, Paim L. Pesquisa convergenteassistencial: um desenho que une o fazer e o pensar na prática assistencial em saúde-enfermagem. $2^{\mathrm{a}}$ ed. Florianópolis (SC): Insular; 2004.

6. Costa MP, Sturtz G, Costa FPP, Ferreira MC, Filho TEP. Epidemiologia e tratamento das úlceras de pressão: experiência de 77 casos. Acta Ortop Bras. 2005; 13(3):124-33.

7. Leininger M. Culture care diversity and university: a theory of nursing. New York (US): National League for Nursing; 1991.

8. Freire P. Pedagogia do oprimido. $37^{\mathrm{a}}$ edição. Rio de Janeiro (RJ): Paz e Terra; 2003.

9. Bardin L. Análise de conteúdo. Lisboa (PT): Edições 70, 1997.

10. Neri AL, Sommerhalder C. As várias faces do cuidado e do bem-estar do cuidador. In: Neri, AL, organizadora. Cuidar de idosos no contexto da família: questões psicológicas e sociais: Campinas (SP): Editora Alínea; 2006. p.9-63.

11. Freire P. Extensão ou comunicação. $12^{a}$ ed. Rio de Janeiro (RJ): Paz e Terra, 2002.

12. Vasconcelos MLMC, Brito RHP. Conceitos de educação em Paulo Freire: glossário. Petrópolis (RJ): Vozes, 2006.

13. Ferreira MA, Figueiredo NMA. Os mecanismos disciplinadores do hospital: As (os) enfermeiras (os) e o poder sobre o corpo do cliente hospitalizado. Esc Anna Nery Rev. Enferm. 1997 Set; 1(1):103-16.

14. Goffman E. Manicômios, prisões e conventos. $4^{\mathrm{a}} \mathrm{ed}$. São Paulo (SP): Perspectiva; 1987.

15. Vasconcellos C. Planejamento do processo de construção do conhecimento em sala de aula. Revista de Educação AEC. 1990; 19(75):29-39.

16. Meier MJ. Tecnologia em enfermagem: o desenvolvimento de um conceito [tese]. Florianópolis (SC): Universidade Federal de Santa Catarina. Programa de Pós-Graduação em Enfermagem; 2004.

17. Koerich MS, Backes DS, Scortegagna HM, Wall ML, Veronese AM, Zeferino MT et al. Tecnologias de cuidado em saúde e enfermagem e suas perspectivas filosóficas. Texto Contexto Enferm. 2006; 15(Esp):178-85.

18. Schraiber LB, Mota A, Novaes HMD. Tecnologias em saúde. In: Escola Politécnica de Saúde Joaquim Venâncio, organizadora. Dicionário da Educação Profissional em Saúde. Rio de Janeiro (RJ): EPSJV; 2006. 